Original Research

\title{
The Effect of Psychoeducation on Self-Efficacy and Motivation for Taking Treatment in Breast Cancer Patients (Ca Mammae)
}

\section{Hanik Endang Nihayati, Laeli Nurhanifah and Ilya Krisnana}

Faculty of Nursing, Universitas Airlangga, Surabaya, Indonesia

\begin{abstract}
Introduction: Besides being a physiological problem, breast cancer is also a psychological problem. Breast cancer patients are prone to anxiety, depression, stress, fear, and other psychological problems. Prolonged psychological problems that are not resolved lead to impaired self-confidence and motivation to undergo treatment, which has a negative impact on health. Psychoeducation as a psychological therapy as well as providing education is used as a therapy that aims to overcome the psychological problems of breast cancer patients.
\end{abstract}

Methods: This study used a quasi-experimental research design. The population in this study was breast cancer patients (ca mammae) at Prof. Dr. Margono Soekardjo Purwokerto. The sample of this study was 50 respondents obtained with purposive sampling technique. The independent variable of this study is psychoeducation and the dependent variables are self-efficacy and motivation. Data were collected using a general self-efficacy questionnaire and intrinsic motivation inventory as well as an observation sheet. Data were analyzed using the Paired T-Test and Independent T-Test statistical tests with a level of significance $\alpha \leq 0.05$.

Results: There was an effect of psychoeducation to self-efficacy and motivation ( $\mathrm{p}=0.000 ; \mathrm{p}=0.000)$.

Conclusion: This study shows that psychoeducation affects self-efficacy and motivation to undergo treatment in breast cancer patients (ca mammae). Psychoeducation provides information related to breast cancer and stress management methods so that it can increase self-efficacy and motivation to undergo treatment for breast cancer patients.

\section{ARTICLE HISTORY}

Received: October 11, 2020

Accepted: April 13, 2021

\section{KEYWORDS}

breast cancer (ca mammae); psychological; psychoeducation; psychological management

\section{CONTACT}

Hanik Endang Nihayati

$\triangle$ hanik-e-n@fkp.unair.ac.id $\equiv$ Faculty of Nursing, Universitas Airlangga, Surabaya, Indonesia

Cite this as: Nihayati, H. E., Nurhanifah, L., \& Krisnana, I. (2021). The Effect of Psychoeducation on Self-Efficacy and Motivation for Taking Treatment in Breast Cancer Patients (Ca Mammae).Jurnal Ners, 16(1). 96-100. doi:http://dx.doi.org/10.20473/jn.v16i1.22560

\section{INTRODUCTION}

Psychological problems in the form of anxiety or depression should not occur in breast cancer patients (ca mammae) because it will have a negative impact on disease progression and adherence to treatment, in addition to greater stress it can lead to the risk of emotional confusion (Wu et al., 2018). Self-efficacy contributes to motivation in a number of ways including breast cancer patients set goals others set for themselves, how much effort they put in, how long they endure adversity, and how resistant they are to failure (Bandura, 1994). The low level of self-efficacy and motivation to undergo treatment is a determining factor in the success of treatment. Self-efficacy in general has a positive relationship with optimism, self-esteem, internal control and motivation and a negative relationship with anxiety, depression, and trauma. Cancer patients who have high self-efficacy can significantly adapt to life changes better than those who have low self-efficacy (Jerusalem \& Mittag, 1995 cited in Sanaei et al., 2014). Based on research conducted by Mudigdo and Murti (2016), someone with high self-efficacy will also have an effect on improving the quality of life, role function, emotional function, and social function.

Cancer will become a world health problem until it reaches 22 million cases in 2032 and breast cancer is included in the largest number of cases (Momenimovahed \& Salehiniya, 2019). In 2012, 
breast cancer was the highest type of cancer, mostly experienced by women, with 1.7 million new cases and an estimated 521,900 deaths (American Cancer Society, 2015). In the United States, the mortality rate for breast cancer sufferers in 2017 was 40,610 patients of all age levels, while the incidence rate of breast cancer was 316,120 sufferers of all age levels (Hodge et al., 2015). In Indonesia, the number of breast cancer cases in 2013 reached 61,682 cases. The percentage of new breast cancer cases was $43.3 \%$ and the death rate was $12.9 \%$ (Torre et al., 2015). Meanwhile, in Central Java, the number of breast cancer cases in 2013 reached 11,511 with the highest number of cases in Indonesia (Deprtemen Kesehatan Republik Indonesia, 2013). In Banyumas district alone in 2012 there were 133 cases of breast cancer (Dinas Kesehatan Provinsi Jawa Tengah, 2014).

Based on this description, the importance of psychoeducational interventions for the psychological impact of breast cancer patients that have an impact on self-efficacy and increase motivation to undergo treatment in breast cancer patients is needed. With the existence of stages of psychoeducation, including identifying problems (breast cancer), providing knowledge related to breast cancer, and stress management, it is hoped that self-efficacy and motivation to undergo breast cancer treatment will increase.

\section{MATERIALS AND METHODS}

Population of this research was patients with breast cancer undergoing chemotherapy in Margono Soekardjo Purwokerto Hospital. The sample of this research was based on inclusion and exclusion criteria. The inclusion criteria consisted of female gender, age range 18-60 years, breast cancer stage IIII. The exclusion criteria in this study were critical patients, and patients with mental disorders. The procedure involved taking informed consent as agreement between researcher and patient. In the first week, the researcher used GSE and motivation instrument to both groups as pretest. In the second week, the researcher conducted psychoeducation to the treatment group. In the third week, the researcher conducted posttest to both groups. The research used a quantitative quasi-experimental research design. The sampling technique used in this study is a non-probability sampling method, namely purposive sampling. Statistical tests used paired T-test and Independent T-Test. The sample size in this study was 50 respondents (25 treatment group, 25 control group).

\section{RESULTS}

Demographic characteristics data describe things related to research respondents. There are five variables in the demographic data characteristics of respondents. The description of the distribution of demographic characteristics (Table 1), the results of self-efficacy (Table 2) and motivation (Table 3) are as follows.
Table 1. Characteristics of Breast Cancer Survivors $\underline{(n=25)}$

\begin{tabular}{ccc}
\hline $\begin{array}{c}\text { Respondent } \\
\text { Characteristics }\end{array}$ & Treatment & Control \\
\cline { 2 - 3 } & $\mathrm{N}(\%)$ & $\mathrm{N}(\%)$ \\
\hline Age group(year) & $1(2.8)$ & $1(2.8)$ \\
$18-30$ & $4(11.1)$ & $3(8.3)$ \\
$31-40$ & $11(30.6)$ & $12(33.3)$ \\
$41-50$ & $9(25.0)$ & $9(25.0)$ \\
$51-60$ & & \\
Education & $15(41.7)$ & $16(44.4)$ \\
Primary & $4(11.1)$ & $5(13.9)$ \\
Intermediate & $3(8.3)$ & $3(8.3)$ \\
Secondar & $3(8.3)$ & $1(2.8)$ \\
University & & \\
Marital status & $0(0.0)$ & $1(2.8)$ \\
Single & $22(61.1)$ & $21(58.3)$ \\
Married & $3(8.3)$ & $3(8.3)$ \\
Widowed & & 1644.4 \\
Occupation & $16(44.4)$ & 12.8 \\
Not working & $1(2.8)$ & 12.8 \\
Traders & $3(8.3)$ & 719.4 \\
Civil servants & $5(13.9)$ & 25100 \\
Others & & \\
Stage & $2(5,6)$ & $3(8.3)$ \\
One & $12(33.3)$ & $12(33.3)$ \\
Two & $11(30.6)$ & $10(27.8)$ \\
Three & & \\
\hline &
\end{tabular}

In Table 1, demographic data show that breast cancer respondents (ca mammae) in the treatment group are more in the age range $41-50$ years $(30.6 \%)$ as well as in the treatment group $(33,3 \%)$. In the treatment group, there is more elementary education $(41.7 \%)$ as well as the control group (44.4\%). In the treatment group those who were married amounted to $61.1 \%$ while in the control group it amounted to $58.3 \%$. Respondents in the treatment group and the control group mostly did not work, namely $33.3 \%$, respectively.

Table 2 shows the level of self-efficacy in the treatment group before the intervention was carried out with as many as 12 people in the high category and after the intervention this increased to 15 people. This high category has the largest number of respondents compared to the low and medium categories. Whereas, in the control group, the level of self-efficacy before the intervention with the high category was nine people and after the intervention was 10 people. However, the low category has the highest number of respondents after treatment, namely 13 people. In the paired t-test in the treatment group, the value $\mathrm{p}=0.000$ was obtained using the critical limit $(\alpha) 0.05$, which means that there is a significant difference between the value of selfefficacy before and after psychoeducation therapy.

Table 3 shows the level of motivation of the treatment group before intervention in the high category as many as nine people and after the intervention this increased to 15 people. However, the medium category in the treatment group was more than the low and high categories, namely as many as 14 people. Whereas in the control group the level of motivation before the intervention with the 
Table 2 .The Results of Self-Efficacy Before and After being Given Psychoeducation Therapy in the Treatment and Control Groups of Breast Cancer Patients (Ca Mammae) $(n=25)$.

\begin{tabular}{|c|c|c|c|c|c|c|c|c|}
\hline \multirow{3}{*}{ Self Efficacy $(N=50)$} & \multicolumn{4}{|c|}{ Treatment } & \multicolumn{4}{|c|}{ Control } \\
\hline & \multicolumn{2}{|c|}{ Pre Test } & \multicolumn{2}{|c|}{ Post Test } & \multicolumn{2}{|c|}{ Pre Test } & \multicolumn{2}{|c|}{ Post Test } \\
\hline & $\mathbf{n}$ & $\%$ & $\mathbf{n}$ & $\%$ & $\mathbf{n}$ & $\%$ & $\mathbf{n}$ & $\%$ \\
\hline Low & 5 & 20 & 0 & 0 & 6 & 24 & 2 & 8 \\
\hline Moderate & 8 & 32 & 10 & 40 & 10 & 40 & 13 & 52 \\
\hline High & 12 & 48 & 15 & 60 & 9 & 36 & 10 & 40 \\
\hline Paired T-test & \multicolumn{4}{|c|}{$p=0.000$} & \multicolumn{4}{|c|}{$p=0.083$} \\
\hline Independent T-Test & $\mathrm{p}=0$. & & & & & & & \\
\hline
\end{tabular}

Table 3. Motivation Results Before and After being Given Psychoeducation Therapy in the Treatment and Control Groups of Breast Cancer Patients (Ca Mammae) (n=25).

\begin{tabular}{|c|c|c|c|c|c|c|c|c|}
\hline \multirow{3}{*}{ Motivation $(\mathrm{N}=50)$} & \multicolumn{4}{|c|}{ Treatment } & \multicolumn{4}{|c|}{ Control } \\
\hline & \multicolumn{2}{|c|}{ Pre Test } & \multicolumn{2}{|c|}{ Post Test } & \multicolumn{2}{|c|}{ Pre Test } & \multicolumn{2}{|c|}{ Post Test } \\
\hline & $\mathbf{n}$ & $\%$ & $\mathbf{n}$ & $\%$ & $\mathbf{n}$ & $\%$ & $\mathbf{n}$ & $\%$ \\
\hline Low & 7 & 28 & 0 & 0 & 0 & 0 & 0 & 0 \\
\hline Moderate & 9 & 36 & 14 & 56 & 13 & 52 & 14 & 56 \\
\hline High & 9 & 36 & 11 & 44 & 12 & 48 & 11 & 44 \\
\hline Paired T-test & \multicolumn{4}{|c|}{$p=0.000$} & \multicolumn{4}{|c|}{$p=0.103$} \\
\hline Independent T-Test & $\mathrm{p}=0$. & & & & & & & \\
\hline
\end{tabular}

high category was 12 people and after the intervention was 11 people. The medium category is the largest category after the intervention with a total of 14 respondents. Paired t-test with critical limits $(\alpha)$ 0.05 , in the treatment group after psychoeducation therapy was 0.000 , less than 0.05 ; this means that there is a significant difference between the motivation values before and after psychoeducation therapy. The result of the paired t-test motivation in the control group was $\mathrm{p}=0.103$ with a critical limit $(\alpha)$ of 0.05 ; this means that there is no significant difference between the motivation values before and after psychoeducation therapy because the p-value is greater than $\alpha$.

\section{DISCUSSION}

\section{Self-Efficacy}

Psychoeducation is effective in improving attitudes because it includes several theories and practices (Lukens \& McFarlane, 2004; Snethen \& Warman, 2018; Taylor-Rodgers \& Batterham, 2014). Psychoeducation is important because it can increase the knowledge and cognitive abilities of clients and families so that it can reduce anxiety or stress (Beshai et al., 2019; Stuart, 2014). The results of the study based on the category of the level of self-efficacy showed that, in the treatment group, it was found that the self-efficacy of undergoing treatment for breast cancer patients, mostly before the intervention (pretest), had high self-efficacy, while after the study, the level of self-efficacy was fixed.

Low levels of self-efficacy can occur before psychoeducation intervention is carried out, because breast cancer patients think that they have little hope of recovery, so they think that treatment is not optimal. This is related to the statement "if I want to try hard, I can solve the problem related to my current illness". Most of the statements in this questionnaire chose to strongly disagree with the reason that most of them had tried various kinds of treatment but the results obtained were not completely satisfactory. Apart from that, in the statement "whatever happens I am ready to handle it", most of the respondents strongly disagree because they think that they are not ready to accept the harsh reality that will happen to them someday. After the psychoeducation intervention was carried out, agreement as to the statement "if I want to try hard, I can solve the problem related to my current illness" is proven by their statement that they will undertake alternative medicine. In the statement "whatever happens, I am ready to handle it", most of the respondents chose to answer disagree, they are still adapting to current cancer conditions.

The increasing level of self-efficacy is also influenced by the information obtained through psychoeducation (Reins et al., 2019; Shah et al., 2014). This statement is evidenced by the results of the posttest in the treatment group after being given psychoeducation intervention, which shows that the level of self-efficacy is increasing. This also shows that psychoeducation intervention has an effect on selfefficacy.

\section{Motivation}

In this study, the motivation to undergo breast cancer treatment in general showed a change, namely the treatment group showed an increase in respondents who had a motivation level for treatment as indicated by the percentage of the mean value after the posttest. Psychoeducation is a combination of psychotherapy 
and educational interventions (Anchan \& Janardhana, 2020; Hudak \& Gallo, 2010; Petre et al., 2021) by looking at potential threats or life development and explaining individual coping strategies to adapt critically in the patient's life, namely through education or what is called psychoeducation (Brown, 2011). Psychoeducation is important because it can affect a person's psychology and have a big effect on the ability to respond (Abedini et al., 2020; Alvidrez et al., 2005).

Researchers argue that psychoeducation is an extrinsic motivation that comes from research. Researchers provide information related to breast cancer and teach how to manage stress. Researchers are said to be the source of increased extrinsic motivation because they are one of the external factors forming motivation.

The level of motivation before and after the psychoeducation intervention was different. The existence of this difference is based on the statement of respondents who mostly chose to strongly disagree before the intervention was carried out, namely the statement "I believe cancer treatment is beneficial for me" and the statement "I feel happy if I do cancer treatment and feel close to cancer treatment" (Barnes et al., 2018; Gür et al., 2017). Respondents thought that taking medication would waste a lot of money while the amount of money needed was so great and they themselves were still experiencing economic difficulties. After a psychoeducational intervention, the statement "I believe cancer treatment is beneficial for me" was agreed.

\section{CONCLUSION}

The conclusion of the research regarding the effect of psychoeducation on self-efficacy and motivation to undergo treatment in breast cancer patients (ca mammae) is that the level of self-efficacy pre and post psychoeducation intervention in breast cancer patients (ca mammae) shows a significant difference between treatment groups and control, or, in other words, psychoeducation can increase self-efficacy in undergoing treatment in breast cancer patients.

The pre and post motivation level of psychoeducation intervention in breast cancer patients (ca mammae) showed a significant difference between the treatment group and the control group, or in other words, psychoeducation could increase motivation to undergo treatment in breast cancer patients.

Healthcare professionals should be more aware of the psychology of patients within this group of breast cancer patients in order to meet their needs.

\section{REFERENCES}

Abedini, M., Olfati, F., Oveisi, S., Bahrami, N., Astrologo, L., \& Chan, Y. H. (2020). Examining the effect of a brief psychoeducation intervention based on selfregulation model on sexual satisfaction for women with breast cancer: A randomized controlled trial.
European Journal of Oncology Nursing , 47, 101673. https://doi.org/10.1016/j.ejon.2019.101673

Alvidrez, J., Areán, P. A., \& Stewart, A. L. (2005). Psychoeducation to Increase Psychotherapy Entry for Older African Americans. The American Journal of Geriatric Psychiatry, 13(7), 554-561. https://doi.org/10.1097/00019442-20050700000003

American Cancer Society. (2015). A Guide to chemotherapy. American Cancer Society. https://www.cancer.org/treatment/treatmentsand-side-effects/treatmenttypes/chemotherapy.html

Anchan, V., \& Janardhana, N. (2020). Transformation of attitude through brief psychoeducation program for the husbands of women with postpartum psychiatric disorders. Asian Journal of Psychiatry, 51, 101841. https://doi.org/10.1016/j.ajp.2019.101841

Bandura, albert. (1994). Self-efficacy. In V.S. Ramachaudran (Ed.), Encyclopedia of human behaviour (pp. 71-81). Academic Press.

Barnes, R. D., Ivezaj, V., Martino, S., Pittman, B. P., Paris, M., \& Grilo, C. M. (2018). Examining motivational interviewing plus nutrition psychoeducation for weight loss in primary care. Journal of Psychosomatic Research, 104, 101-107. https://doi.org/10.1016/j.jpsychores.2017.11.01 3

Beshai, S., Watson, L. M., Meadows, T. J. S., \& Soucy, J. N. (2019). Perceptions of Cognitive-Behavioral Therapy and Antidepressant Medication for Depression After Brief Psychoeducation: Examining Shifts in Attitudes. Behavior Therapy, 50(5), 851-863. https://doi.org/10.1016/j.beth.2019.01.001

Brown, L. P. (2011). Nurse Education in Practice Revisiting our roots : Caring in nursing curriculum design. Nurse Education in Practice, 11(6), 360364. https://doi.org/10.1016/j.nepr.2011.03.007

Deprtemen Kesehatan Republik Indonesia. (2013). Riset Kesehatan Dasar. https://doi.org/1 Desember 2013

Dinas Kesehatan Provinsi Jawa Tengah. (2014). Profil Kesehatan Provinsi Jawa Tengag.

Gür, F., Can Gür, G., \& Okanll, A. (2017). The Effect of the Cognitive-behavioral Model-based Psychoeducation and Exercise Intervention on Quality of Life in Alcohol Use Disorder. Archives of Psychiatric Nursing, 31(6), 541-548. https://doi.org/10.1016/j.apnu.2017.07.005

Hodge, F. S., Itty, T. L., Cadogan, M. P., Martinez, F., \& Pham, A. (2015). The cultural constructs of cancerrelated fatigue among American Indian cancer survivors. Supportive Care in Cancer. https://doi.org/10.1007/s00520-015-2902-7

Hudak, \& Gallo. (2010). Keperawatan Kritis (6th ed.). EGC.

Lukens, E. P., \& McFarlane, W. R. (2004). Psychoeducation as Evidence-Based Practice: Considerations for Practice, Research, and Policy. Brief Treatment and Crisis Intervention, 4(3), 205- 
$225 . \quad$ https://doi.org/10.1093/brieftreatment/mhh019

Momenimovahed, Z., \& Salehiniya, H. (2019). Epidemiological characteristics of and risk factors for breast cancer in the world. Breast Cancer: Targets and Therapy, Volume 11, 151-164. https://doi.org/10.2147/BCTT.S176070

Mudigdo, A., \& Murti, B. (2016). The Effect of SelfEfficacy, Family Support, and Socio-Economic Factors on the Quality of Life of Patients with Breast Cancer at Dr . Moewardi Hospital, Surakarta. 1(3), 182-194.

Petre, L. M., Gemescu, M., \& Bulgari, D. (2021). Using artistic activities within experiential psychotherapy to alleviate the psychological consequences of female infertility. The Arts in $\begin{array}{lll}\text { Psychotherapy, } & 101758 .\end{array}$ https://doi.org/10.1016/j.aip.2021.101758

Reins, J. A., Boß, L., Lehr, D., Berking, M., \& Ebert, D. D. (2019). The more I got, the less I need? Efficacy of Internet-based guided self-help compared to online psychoeducation for major depressive disorder. Journal of Affective Disorders, 246, 695705. https://doi.org/10.1016/j.jad.2018.12.065

Sanaei, H., Ali, S., \& Jamshidifar, Z. (2014). Effectiveness of Mindfulness Training on SelfEfficacy of Patients Infected by Breast Cancer. Procedia - Social and Behavioral Sciences, 159, 426-429. https://doi.org/10.1016/j.sbspro.2014.12.400

Shah, L. B. I., Klainin-Yobas, P., Torres, S., \& Kannusamy, P. (2014). Efficacy of
Psychoeducation and Relaxation Interventions on Stress-Related Variables in People With Mental Disorders: A Literature Review. Archives of Psychiatric Nursing, 28(2), 94-101. https://doi.org/10.1016/j.apnu.2013.11.004

Snethen, C., \& Warman, D. M. (2018). Effects of psychoeducation on attitudes towards individuals with pedophilic sexual intrusive thoughts. Journal of Obsessive-Compulsive and Related Disorders, 19, 92-98. https://doi.org/10.1016/j.jocrd.2018.10.001

Stuart, G. W. (2014). Principles and Practice of Psychiatric Nursing-E-Book. Elsevier Health Sciences.

Taylor-Rodgers, E., \& Batterham, P. J. (2014). Evaluation of an online psychoeducation intervention to promote mental health help seeking attitudes and intentions among young adults: Randomised controlled trial. Journal of Affective Disorders, 168, 65-71. https://doi.org/10.1016/j.jad.2014.06.047

Torre, L. A., Bray, F., Siegel, R. L., Ferlay, J., LortetTieulent, J., \& Jemal, A. (2015). Global cancer statistics, 2012. CA: A Cancer Journal for Clinicians, 65(2), 87-108. https://doi.org/10.3322/caac.21262

Wu, P., Chen, S., Huang, W., \& Chang, S. (2018). Effects of a Psychoeducational Intervention in Patients With Breast Cancer Undergoing Chemotherapy. oo(0), 1-14 